\title{
Bioethics and Intersex: "Time out”. A paradigm SHift on Intersex Management in the Spanish context
}

\author{
INTERSEXUALIDAD Y BIOÉtICA: "TIEMPO MUERTO". CAMBIO DE PARADIGMA EN LA GESTIÓN \\ DE LAS VARIACIONES INTERSEXUALES EN EL CONTEXTO ESPAÑOL
}

\author{
Nuria Gregori Flor*; (S.) García Dauder**; Inmaculada Hurtado \\ García* *
}

* Hospital General Universitario de Elche; * Universidad Rey Juan Carlos; *** Universidad CEU Cardenal Herrera; interemergen@gmail.com; dauder26@hotmail.com; inmaculada.hurtado@uchceu.es

\begin{abstract}
Historia editorial Abstract
Recibido: 10-05-2016

Primera revisión: 08-05-2017

In medical literature about management of Intersex, there has been considerable debate addressing ethical issues on medical practice -informed consent, parents' rights to make decisions about surgery on infants or whether children should be surgically altered to suit the binary gender norms of society-. Selecting the best management for the various intersex situations can be complex, and several proposals concerning ethical principles have emerged. During the annual meeting of the Spanish support group Grapsia, we coordinated a "Bioethics and Intersex/DSD" discussion group, with the aim to identify some key elements to enhance socio-health care for people with intersex variations and their families. On the one hand, it is necessary to consider the particularities of each context and the constraints imposed by the structure and organization of each country's health systems. On the other hand, it is crucial to include insights of patients taking part in support groups and their families.
\end{abstract}

\section{Resumen}

Palabras clave

Intersexualidad

Ética

Contexto español

Grupos de apoyo
Existe un debate considerable sobre cuestiones éticas que afectan la práctica médica de las condiciones intersexuales: el consentimiento informado, los derechos de los padres para tomar decisiones sobre la cirugía de sus bebés o si éstos deben ser alterados quirúrgicamente para adaptarse a las normas binarias de género de la sociedad. Seleccionar la mejor gestión para las diversas situaciones intersexuales puede ser complejo, y han surgido varias propuestas sobre principios éticos. Durante la reunión anual del grupo de apoyo español Grapsia, coordinamos un grupo de discusión "Bioética e Intersex/DSD", con el objetivo de identificar elementos clave para mejorar la atención socio-sanitaria para las personas con variaciones intersexuales y sus familias. Por un lado, es necesario considerar las particularidades de cada contexto y las restricciones impuestas por la estructura y organización de los sistemas de salud de cada país. Por otro lado, es crucial incluir las ideas de los pacientes que participan en grupos de apoyo y sus familias.

Flor, Nuria Gregori; García Dauder, (S.) \& Hurtado García, Inmaculada (2018). Bioethics and Intersex: "Time out”. A paradigm shift on Intersex Management in the Spanish context. Athenea Digital, 18(2), e1899. https://doi.org/10.5565/rev/athenea.1899

\section{Introduction}

"Intersex" is an umbrella term used for a variety of conditions in which a person is born with a reproductive or sexual anatomy that does not fit the typical definitions of a female or male body. This variation of sexed bodies has been medically treated, in most cases in the absence of a health problem: that is, a social problem is medically 
cured (Kessler, 1998). In the middle of the nineties, beyond the Spanish context and especially in the North American, emerged a whole movement of patients and activists who challenged these medical practices, mainly the absence or lack of information and the surgical procedures they suffered in infancy. For almost fifteen years, many of these activists have denounced the negative outcomes of surgeries -including problems regarding sexual function-, incorrect assignments of gender or individual struggle against depression, shame and guilt. It was during this period, that Alice Dreger (1999) named "the age of consent", that patients campaigned: (1) to be provided with all the information on their condition - completely and honestly-; (2) to limit medical displays commonly known as parades and (3) to be provided with non-pathologized terminology and images - especially those of naked children with squares and black bars on their eyes and those of genitalia procedures. Equally, they requested a delay on cosmetic surgeries, at least until the "affected" people can consent or until the medical professionals have completed exhaustive retrospective research with positive outcomes (Kipnis \& Diamond, 1999). Finally, they called for long-term studies on satisfaction and quality of life of "intersexed" patients (Preves, 2003).

All these complaints led to the "healthcare paradigm shift" (Tamar-Mattis, 2008) and consequently many professionals conceded that a new paradigm on "intersexuality" treatment was to be established. Bruce Wilson and William Reiner (1998) in particular stated that the old technocentric treatment paradigm was being replaced by a new ethically informed and "patient-centered care". These authors, along with other ones, hold that the old paradigm was untenable since it contradicted one of the medical axioms: "First, do not harm" - Primum, non nocerum(Kipnis \& Diamond, 1999; Ford, 2001). The main premises of this new model include complete and honest information to parents as well as patients, peer support (SG), psychological support and limitation of early surgeries (Diamond \& Sigmundson, 1997).

In Spain, among all, the best known guideline for medical specialists on intersex/DSD healthcare is the Consensus Statement on Management of Intersex Disorders (Lee, Houk, Ahmed \& Hughes, 2006). This consensus, known as the Chicago Consensus, settled a standard of care in America and Europe that today is known as "Optimal Clinical Management of Individuals with DSD". This is the moment when the term DSD (Disorders of Sex Development) was introduced, to refer to intersexuality (intersex), or to older terms such as hermaphroditism or pseudohermaphroditism (Lee et al., 2006, p. 488). According to the Chicago Consensus, this change in the terminology had the objective of destigmatising intersexuality, as previous labels were "controversial and potentially pejorative by patients and 
also confusing or misleading by parents and health professionals" (Lee et al., 2006, p. 488). However, this proposal has not been shared by all groups and social actors (García-Dauder \& Romero, 2012). Many other people and groups have criticized the use of the notion "disorder" as it implies a step backwards in destigmatization. They maintain that: (1) "children are not disorders" (Baechler, 2006; Hinkle, 2010), (2) the use of the acronym DSD hides a stigmatized vision (Simmonds, 2006) and (3) new classifications based on karyotype (i.e., "46,XX DSD") are confusing (Damiani, 2006; Machado, 2008; Sieldberg, 2006).

We interpret the term DSD as differences, not disorders. The term has been used in this same way by other professionals (Greenberg, 2012) and groups, such as "Bioethics and Intersex" within the German DSD/Intersex Network (Wiesemann, 2009). The use of other labels such as "Sexual Development Variations" (SDV) (Diamond \& Beh, 2006; Simmonds, 2006) or "Divergences" (Divergence of Sex Development) (Reis, 2007) has also been suggested. In this article we use these terms according to the personal choice of the participants, but broadly speaking, we will use the term intersex, emphasizing the variability of patterns or routes in sex differentiation (chromosomal, gonadal, hormonal or genital).

But, can we apply these debates and controversies to the Spanish context? How has the care of people with "intersexual conditions/DSD" been during this period in Spain? What obstacles or issues have medical professionals as well as "affected" people and support groups encountered? What sorts of demands have been expressed? Without a doubt, there is a gap regarding these issues in Spain and in Spanish language, as most of the bibliography is in English. From this lack of information came the idea of encouraging a meeting or discussion group between experts in intersex/DSD from different sectors and contexts, different biomedical professionals and different social sciences, and support groups - "affected" and their families-, to finally determine the state of the art in Spain.

\section{Objective and methodology}

For the identification and discussion of the main problems of intersex management in the Spanish context, the authors of this article, within the research project Cartographies of the body: Biopolitics of Science and Technology (Spanish National Research Council, Madrid), encouraged the Bioethics and Intersex/DSD Discussion Group during the annual meeting of the support group for Androgen Insensibility Syndrome (AIS) and Related Syndromes -GrApSIA. This meeting was not the first occasion to share projects between support group GrApSIA and the 
authors of this article. We have a long-term relationship of more than ten years sharing experiences, introducing psychosocial perspective in the group, organizing events and meetings, etc. Before this alliance, GrApSIA support group had an exclusive clinic and medical perspective, and we, as psychosocial researchers, had only a theoretical perspective of the experiences and necessities of individuals living with intersex variations/DSD and their relatives.

In this article we present the result of this discussion group, as the result of two hours of debate. The management of any intersex condition is very unwieldy and the reflections that we expose can only be taken as a partial and superficial approach. In order to begin the discussion, rather than using a debate script, we introduced the topics and the debate flowed according to the needs of every participant, in a spontaneous and dynamic way. Thus, we avoided directing responses when the group presented obstacles or needs.

Some questions did not necessarily crop up during the debate, others were addressed superficially. In short, the solutions put forward may be considered as proposals for thinking, open-ended questions, doubts, concerns and contradictions. In fact, we were convinced that only through a dialogue between all actors we could move towards an optimal care of individuals with intersex variations.

We must point out that in writing this text we have used the literal transcript of the participants as a methodological option. It is important to use this format "to illustrate the oscillation between micro and macro analysis that comes from combining the methodologies of ethnography and critical social research; looking in detail at the informants' testimony, but broadening this out to a consideration of structural and historical issues" (Wainwright, 1997, p. 15). The goal was to avoid interpreting and constructing informants discourses as far as possible and demonstrate the supremacy of subjectivity (Geertz, 1973; Goodall, 2000). The meeting was recorded and transcribed, thus, when reading it, we should take into account that colloquial expressions and language are the result of the spontaneous situation.

Twelve people have finally taken part in the Bioethics and Intersex/DSD Discussion Group, a group created especially for the occasion and met on October 20, 2012: 6 GrApSIA members, 2 parents -a mother Parent 1 and a father Parent 2-, 3 "affected" - Affected 1, Affected 2 and Affected 3-, and a psychotherapist and "af fected" person -Affected-Professional 1-; researchers and physicians who work on intersex/DSD in Spain - a paediatric endocrinology specialist (Professional 3); an endocrinologist from the University Hospital of Vigo (Professional 4); Dau García Dauder, psychologist of the University Rey Juan Carlos (Madrid) (Professional 
5) and Nuria Gregori Flor, nurse and anthropologist of the University of Valencia (Professional 6)-. Besides, since some neighboring countries such as England and Germany have a long trajectory in bioethical management of intersex/DSD, we invited an adult endocrinologist from London (Professional 2) and a nurse and anthropologist from the working group "Bioethics and Intersex" within the German Network DSD/Intersex (Professional 1), in order to enrich debate and discussion.

We, as authors, had sometimes a complicated multiposition during the meeting: as participants, as psychosocial researchers, as chairperson, and as event organizer. We tried to handle this constraint by acting more as a chairperson and making only a few notes during the meeting.

The main goal of this meeting was to create a place where people can discuss these controversies promoting the exchange of knowledge to enhance intersex/DSD healthcare. What is new about this initiative, as for the Spanish State, lies in the heterogeneity of the participants. "Affected" people and their families, biomedical professionals and researchers - paediatricians, endocrinologists, nurses, psychologists-, and other researchers and psychosocial scientists - social psychologists, anthropologistsare groups that are not used to working together, looking for joint solutions. In this context, both academic and professional knowledge as well as voices of experience were legitimized as "expert knowledge", both sides going hand in hand.

Unlike the Spanish State, in other contexts -UK or Australia- there is greater awareness and long-established teams formed by support groups and clinical professionals. Despite the poor documentation, there are a growing number of publications recognising the role of support groups in enhancing and promoting care, in providing information and increasing awareness (Bartlett \& Coulson, 2011; Creighton, Minto, Liao, Alderson \& Simmonds, 2004; Cull, 2002; 2005; Cull and Simmonds, 2010; GrApSIA, 2015; Warne, 2003).

Finally, the units structuring our analysis were the following: the way of naming; living with intersex/DSD (nature of the problems that have arisen to people diagnosed with an "intersex condition/DSD", care needs and the role of support groups); and solutions/strategies for a new model (health care/medical care, sociocultural aspects, from the old model to a new patient and support group-centered model). All topics discussed during the meeting were included in the analysis. Only discourses that are redundant or that did not produce new information were not included. 


\section{Problems, solutions and solvers}

Many of the questions considered throughout the meeting were about the difficulty of passing from an old model of clinical management of "intersexuality/DSD", a one-way paternalistic model, to a new patient-centered model of care. Under this new schema, patients are no longer a passive recipient of information, medical solutions and treatments. In contrast, patients take part actively in decision-making. And in doing so, they have to assume new responsibilities and risks and share them with the professionals in charge.

One of the first turning points that set the debate in the discussion group focused on the way of naming Intersex/DSD. Within Spain, the term DSD has not been accepted willingly by all social actors, "affected" people and support groups. In fact, a consensus was not reached within participants of the discussion group. One of the attendants to the meeting argued that words should not carry so much weight, "To me black is black and white is white and I don't worry about names" (Affected 2, Discussion Group, October 2012). There was disagreement between the seminar attendants, "Words matter, because when you say I have a pathology, this is making me think of myself in one or other way, this is changing my selfimage. Emotionally, something is affecting me. Words do have connotations" (Affected-Professional 1, Discussion Group, October 2012).

In fact, when revising this article with some members of GrApSIA, the question of terminology caused discordance between other members of the group who were not present in the meeting. One member wrote in an e-mail:

There's something I keep thinking of lately, the use of 'intersexuality'. To me, I'd rather say, when possible, intersex conditions or states. Why? I think the term 'intersexuality' may be misleading. (Maybe not in a scientific publication, where people are experts in the matter, but these expressions are transferred to colloquial speech.) To make myself clear, I would say 'intersexuality' has got the word sexuality in it, so it may lead us to the idea of sexual option, such as heterosexuality/ homosexuality, and we know intersexuality isn't any of those, nor a way of developing individual sexuality. That's why I'd rather use 'intersex conditions or states' which refer to a state or condition in the person as a whole. Of course, this is just my opinion. I believe we think too much about DSD (and that's ok with me), but maybe we are neglecting that part a little bit (Grapsia member, Personal communication, December 2012).

Despite the lack of consensus in the discussion group with regard to the most appropriate terminology or to whether "intersex/DSD" is a pathology or a varia- 
tion in the most common types of sexual anatomy, consensus was reached on the issues they face when living with it. One of the problems is related to the low fre quency of these conditions, which have subsequently been considered under the umbrella of Rare Diseases (RD) or low prevalence diseases by FEDER (Spanish Federation for Rare Diseases, Federación Española de Enfermedades Raras). Josep Canals (2002, p. 190) defines RD as "diseases of very low incidence that, due to this scarcity, lead to specific situations of vulnerability when facing the uncertainty of diagnosis and the difficulty of finding a suitable treatment". The ignorance of most of these realities can be applied to many doctors, a fact which has resulted in patient vulnerability. Such lack of knowledge is especially jeopardizing for the cases treated in primary health care, where physicians play a determining role in referring these cases to a suitable specialist. Hence, the itinerary of a person affected with a RD is usually an odyssey filled with false diagnosis, endless re ferrals to different specialists, long periods without a diagnosis and some other worrisome situations.

This problem refers to structural issues; in other words, it is related to the structure and organization of the Spanish health system itself: competences, difficulty in accessing professionals with suitable work experience, obstacles to reaching a diagnosis and a suitable treatment, troubles in finding new professionals in order to seek a second clinical judgement in another hospital or region (Gregori, 2015; 2016). Parent 1 explained:

We, people living in provinces, are very likely to run into uninformed specialists, so we end up with people that think they are up to date, but they are not. In the case of a girl with Complete Androgen Insensitivity Syndrome (CAIS) they gave us solutions that were feasible some time ago, such as gonads extirpation. That wasn't just one option of several, it was the only choice presented. But there is now a tendency to wait for pubertal sex development. And therefore we, parents, have to be the ones looking for support out of our province, we have to challenge public administration to get out of here and find these up-to-date doctors willing to help us (Parent 1, Discussion Group, October 2012).

In Parent 1's case, the specialist recommended gonadectomy, but they rejected the doctor's advice after contacting GrApSIA. The group told them about other cases and experiences of "affected", so they finally accessed other professionals recommended by the support group (SG):

Our daughter, she's 14, would have already undergone surgery. That would have been a final decision. I would like us to become a reference place, at 
least in Madrid and Barcelona, to turn to when you face a situation like this, at least to have that second opinion with the help of the support group. In some provinces we are really unprotected (Parent 1, Discussion Group, October 2012).

Parent 1's view will be the building hypothesis and conclusion of the meeting: support groups are becoming expert agents and pressure groups triggering structural, familial and social changes. In this same line, Professional 3 pointed out the two main elements that had triggered all the changes in the paediatrics field in the past 10-15 years:

First, the scientific and technological developments, which have allowed us to better know DSD causes and origins so as to understand the diagnosis, and to a lesser extent, to make a reliable forecast on treatment adequacy. And this also comes along with patient experience and society questioning some medical actions, such as gonadectomies in CAIS cases or surgery to the external genitalia, which currently is a hotly debated question (Professional 3, Discussion Group, October 2012).

Parent 2 demanded the development of, via medical teams and support groups working together:

Some sort of protocol requiring a medical professional body composed of more than one clinician for the management of this kind of disease. So that somehow, the clinical judgment does not depend on one doctor. Doctors should be obliged to refer these patients to centers of expertise. In a utopian world, that would be applied to all pathologies. But, if not possible at all, at least we should try that with RD (Parent 2, Discussion Group, October 2012).

Other issues referred to the very foundations of the organization of the Spanish healthcare model: type of assistance and care provided, how is the "doctor-patient relationship" established, their rights, obligations and responsibilities. As maintained by Professional 4, "one considerable obstacle of the public health system is that the doctor isn't chosen, you can't request a doctor. In my view, the possibility of choice should be essential to a health system" (Professional 4, Discussion Group, October 2012). Professional 4 also pointed out the common denominator among groups of persons affected by chronic diseases - whether it's diabetes, growth disorders or an intersex condition -: discontent. Thus, the clinician put forward that a displacement in the doctor-patient relationship would bring about a major improvement with regard to the traditional model: "The basis of the doctor-patient relationship is that to be fully heard and understanding to make them understand" (Professional 4, Discussion Group, October 2012). Provide them with clear, sufficient and relevant information and be empathetic. 
The endocrinologist, who was pessimistic regarding this change, brought forward a humanist medicine approach "based on active listening, respect, responsibility and engagement of all actors involved: doctors, patients and parents" (Professional 4, Discussion Group, October 2012). This two-way flow of information enhances clinician's communication skills and attitudes. In this sense, his perspective will move away from the contemporary tendency that understands progress as the technologization and perfection of bodies. The endocrinologist was speaking from his personal experience as a trauma patient: "when colleagues perform X-ray examinations and scanners on you and without further comments they tell you: 'Go and put yourself on the waiting list'. But, what if I don't want to get an operation? What if I don't want to be an athlete?" (Professional 4, Discussion Group, October 2012).

One of the main research questions was: what is the nature of the problems that have arisen for people diagnosed with an "intersex condition/DSD"? Parents and "affected" people from GrApSIA recognized that depending on the problems or demands we identify, we should find different solutions and consequently, profiles of clinicians in charge. According to Affected-Professional 1, we should start diverting attention away from the medical sphere:

We do have a problem. But it isn't a health problem. Our problem is self-confidence... all these prejudices, all about fitting into society. It's a secrecy question. We are ashamed of ourselves, of our body. We hate ourselves. In order to work this out, we don't need a doctor or a medical team. We do need them in some situations, yes. But, what happens to all our insecurities? Our body image fears? Secrecy... I've been silent about it over 20 years. No doctor can fix this. When it comes to showing our body to a partner, the way we feel in intimacy (be it a same-sex or opposite-sex relationship)... No doctor can solve this. It is society that has to change and we as a group or association can be the driving force. We need to work on it personally and socially. If we don't work on it personally, our fears and so on, we will never be that force. We will always feel insecure; we will always think we need them, relying on them. Right, we need information, but doctors are handicapped here. Doctors can do nothing about that, about our hatred and our fear of not fitting in (Affected-Professional 1, Discussion Group, October 2012).

In this sense, Affected 2 admitted:

I say I have a social or familiar pathology. I'm not traumatized for having or not having... I am as I am and that's it. Besides, I accept myself. The problem is that I don't fit in. But it isn't about me; it's about my social and personal milieu. It is my milieu that is making me look like a freak. Then, I'm not a 
freak because what I have or I don't have... I am a freak because they see me as a freak. [...] I don't consider myself ill or sick. I am diseased by these collateral situations caused by this syndrome that are affecting me (Affected 2, Discussion Group, October 2012).

Affected-Professional 1 and Affected 2 statements coincided with the observations made by people with an intersex condition that had been medically treated in the United States by the end of the nineties. Esther Morris (2001), for instance, put it this way: "Not having a vagina was not my problem: having to get one is". These first activist movements have already displaced attention from an ostensible "medical issue", to rigid cultural models that do not accept variability of anatomies and identities (Cabral, 2009). But medicine is part of society. It's not outside of society. As Simmonds points out, "large part of the problem is that medicine has seen itself as 'an ivory tower', as a separate agent that merely reflects society's views. But medicine shapes society's view as well".

Are we talking about medical or psychosocial problems? Are they medical pathologies or are they social and "familiar" pathologies? Without a doubt, answers provided by "affected" outline solutions aiming at psychosocial changes (Alcántara, 2012; García-Dauder, Gregori \& Hurtado, 2015). Affected 3 pointed out:

It is necessary to make a change, in families, society, and health system. Society is not ready to listen to these stories. People have no idea that this exists. And they don't care, either, I think. Maybe they only care to push you away (Affected 3, Discussion Group, October 2012).

Affected-Professional 1 disagreed with Affected 3:

I don't think so. If we did, we would be impressed by people's reaction. They are surprising. In my case I have told it many times, and if I sleep with somebody I also share it with that person. I can tell you that people really, if they are trustworthy and good listeners, reactions are usually positive (AffectedProfessional 1, Discussion Group, October 2012).

As the underlying issue was centered in sociocultural conceptions, which are tediously transformed, participants, mostly parents and "affected", expressed the desire for a better psychological support that will help in dealing with fear of difference, alleviate and orient parents towards supporting their children in the process. According to Parent 1:

For an adult; be able to face it, live a dignified life and lead it as naturally as possible. For parents; how to address the issue with your daughter? Our situation now is where to start, because each girl has their own personality. Our 
daughter is 14 and never asks questions. But we've long been aware of this situation, almost two years now. Two years ago or maybe last year, during our first GrApSIA SG meeting, it was almost impossible to talk about it. Now, we can take that step and talk to our daughter. First thing we told her, two months ago, was that she won't have the period. Immediately, she linked it to not having children. I tried to calm her. I relieved her telling her that you can have children even if you don't conceive them. But she doesn't make questions. It seems she's not accepting her situation. I don't know, maybe she keeps it all to herself or maybe she has no worries for now. I'm waiting for the moment she demands some information (Parent 1, Discussion Group, October 2012).

This statement reveals the stress families feel in managing uncertainty, information and secrecy concerning an intersex condition (Gregori, 2015). In most of the cases, the burden of guilt and recrimination flows from one side to the other in the parents-daughter relationship and, especially, in the mother-daughter relationship. Thus, after these comments, Affected-Professional 1 suggested to the mother that she think about the way she and her husband are dealing with it themselves.

In the light of Parent 1's concern over how to act with her daughter, she received all kinds of advice from the people present in the discussion group. For example, Affected 2 said:

I used to think, why me? What is happening to me? Why am I not like my friends? But at home no one talks. [...] You need to open doors, because she'll probably withdraw. When I was 14 I didn't ask questions, because when I did, everything steered the conversation in the direction they wanted. Now I'm 45 and it's the same tale. If I've been dragged down by these chains of silence is because here everyone's turning a blind eye. Maybe they were waiting for me to ask, but when I tried to pose the questions, maybe my manners were somehow inappropriate (Affected 2, Discussion Group, October 2012).

\section{Affected 1 added:}

I know of some cases and I think all of them have passed that stage. When I was 16 it was negation, defense: pretending that nothing happens. I was offered information. It depends on you, it depends on the person. In the end, I am responsible for that, because I was offered information. My parents were waiting for me to ask. Now, I can't hold them responsible (Affected 1, Discussion Group, October 2012). 
Affected-Professional 1, from her experience as a patient and psychotherapist concluded:

You've said two important things. One is what happens with AIS, because, although no one speaks, you do experience it. If it's a taboo or not, depends on parents' experience. That's why it's important for parents to work on the way they approach what is happening. The other subject is your communication with your daughter. Does she tell you about her fears or insecurities? Many families don't speak about emotional issues, so they don't speak about this, either. Why are you going to talk about this, then? The gaze we get is that of the parents. Parents need to work on this. The best thing is to work on it with the support group and in psychotherapy practice. It's here that these reference groups become meaningful resources. It's not just that my kid goes and asks me about it, what is important is what's happening to the parents. What children feel is directly connected with the family. [...] In child/infant psychology, I support the view of parent intervention as a way of intervening with children/infants. The symptom of the child/infant is that of the family, and parents are responsible for the family (Affected-Professional 1, Discussion Group, October 2012).

Parent 1 doubted that her daughter would be ready to face it, "I think this is a grown-up thing”. To Affected-Professional 1, such statement showed fear of rejection and alien gaze. Thus, she said:

What do you mean by 'it's an adult matter'? What I see, and it's normal, is a tremendous fear that she will finally find out, that this will come to light. I know this first-hand. And I didn't talk about it when I was 14, but twentysomething. There are no wrong or right paths. What we need to know is what happens to a person with this. The problem is the anguish you feel when you think whether she would tell it to anyone. You are filled with anguish, and this has huge implications for your daughter when she's told not to talk about it (Affected-Professional 1, Discussion Group, October 2012).

Affected 2 interrupted to declare she had never spoken about it. Fear of rejection is the most important cause of trouble for parents with regard to their children (Gregori, 2015). They think society is cruel to difference and do not know what to do or say, fearing their words and acts would harm their children even more. Affected 2 replied:

Well, what if your daughter was fat? I've found myself with tiny tits, fat, with short hair... Cruelty is everywhere, at all levels. If they want to hurt your daughter, they will look in her flaws, any flaw: big ears, one leg longer than the other... Well, I suffer with this pathology, you see, and I don't have 
a period. So girls used to laugh at me for that reason. But, for example, it was harder to me when they used to call me fat, or when they told me that I didn't have tits. Or when they called me liar since, despite being the oldest in the class, I didn't have a period. This shouldn't result in trauma or stigma. Everywhere we are subdued to... and this strike needn't be harder than any other. To me the hardest part is what you were remarking. Why do they have to know about it? Why them? It is my intimacy, my privacy. They would know what you want to speak about, but if you don't want, then they won't know. [...] Let me ask you a question. You might think it isn't appropriate. Let me ask you a question. Do you see your daughter as a normal girl? [Parent 1 answers, "Yes"]. Well, that is what I think I should have felt at home, not like a weirdo. Just like any of my siblings. I knew they were hiding something from me, but I thought it was a different story. The last thing I thought of was that it had anything to do with my body. Feeling themselves stigmatized, they have regarded me as something I really wasn't. It's all about talking, being open about everything, not only this. Because if you are open only with this, your daughter will say: 'why are you talking about that?' (Affected 2, Discussion Group, October 2012).

Affected 1 added: "So intense is parents' fear that we get hurt... But in the end you need to assume they will suffer, whatever happens, but in the end they will get by" (Affected 1, Discussion Group, October 2012). The idea that the true affected are parents (Gregori, 2015) was gradually building up in the course of the debate. As stated by Professional 4:

There is something which we shouldn't forget: the feeling of guilt parents might experience when their children are diagnosed with chronic diseases. Many times the ones in need of psychological support are parents, rather than the kid. Children, sensitive and intelligent, sense what's going on and that's why they don't open up. It happens with diabetic children, children of short stature, they shut themselves because their parents aren't natural with them. And this is the vital point, to face issues naturally. Parents need psychologists, too (Professional 4, Discussion Group, October 2012).

Definitely, psychological help to parents was set up as one of the priorities in intersexuality management. Nonetheless, discussion on the psychological professional profile kept going. Would any psychologist be suitable? Would a specifically trained psychologist be recommendable? What assistance can they offer? Parent 1 stated that in many cases parents' experience is dependent on what information they have received and the way it has been provided: 
Parents are the first to know the diagnosis and the way they will address it with their daughter depends on how they receive the diagnosis. Family therapy, which won't be long term but like a shock treatment. Because you feel really lost, and for some people it could be easier, for the distinctive character of every person. This is not covered. And if you found a psychologist, ignorant of all this, he/she may help you as a professional, but, you know... (Parent 1, Discussion Group, October 2012).

Professional 5 agreed, "A psychologist can't assure you anything" and Parent 1 remembered the lack of information on intersexuality most psychologists have. On the contrary, Affected-Professional 1 and Professional 4 attribute less importance to a specific training:

A psychologist needs to know about the human being, be able to listen and evaluate feelings. It's not so different from other things. It's about fear, about the way of living sexuality... Emotions, experiences... And your emotions are going to be similar, similar to hers. It is clear that being informed helps and makes it better, but it is especially important to listen and to know how to accompany in the process (Affected-Professional 1, Discussion Group, October 2012).

While the psychologist or psychotherapist stood as key component in this new model of care, Parent 1 insisted:

I agree with the idea that psychological support is vital to face this subject and move forward. But, what is the problem we have? That first step is medical, facing the diagnosis. And depending on the doctor you find, whether a bad start or a good one, or doubting her or his decisions... If you doubt and mistrust the doctor, first you need to work on this. And now that you're on the way, that you accept the diagnosis, here comes the problem of psychologically bearing it (Parent 1, Discussion Group, October 2012).

Once the need is defined, structural problems in a system which does not offer free psychological care, not to mention the possibility of requesting a therapist of choice, came forward once more: "I don't know about the situation in Great Britain or in other countries, but here, in Spain, there's no psychological support, or maybe there is but it's really poor" (Parent 1, Discussion Group, October 2012). "You have to turn to private services" (Affected-Professional 1, Discussion Group, October 2012). It was also set forth how in some cases even professionals in charge attach no importance to this need or they set it aside:

In these cases counseling is really important. A paediatrician told us once: 'Psychologist? No way! You are her mother; you will know what to tell her. 
You will know what to say in every moment'. It seems you must know everything, as if there was a user's guide or some kind of manual. 'You'll know what you have to do'. But you don't, it's really hard. And you've kind of an inner conflict because it's a complex situation, you don't know how to deal with it and the pain you feel because she's your daughter... You're always suffering in tackling this (Parent 1, Discussion Group, October 2012).

Simmonds (2006) point outs that "when doctors talk of 'counseling' they often mean just the communication of medical information, like 'genetic counseling' (which I think is mainly about the chance of having another affected child). The doctors aren't meaning psychological/emotional counseling/therapy, which is what is really needed. They like to be in control of everything themselves, thinking that their own words, explaining the condition in medical terms should be enough".

\section{New model, new actors}

In view of the lack of sufficient institutional resources - whether due to the lack of skilled professionals or problems referring patients to another specialist in order to obtain a second judgement or the lack of a psychologist, etc.- , the solution to this situation implies a suitable alternative and an ideological shift - a change of model in the doctor-patient relationship. Professional 5 encouraged the two visiting researchers, from England and Germany, to share their view and experience from another European context. In their answers, support groups (SG) (Professional 2) as well as the multidisciplinary team (MDT) - with patient being part of the team (Professional 1)-, rose as strategic places in a paradigm shift. In this shifting, patient SG continue gaining autonomy, becoming the main actors in intersex/DSD care and the principal agents of change in medical practice: "When we contacted GrApSIA, what we needed was support and guidance, directions to know what to do and where to go. The girls in the SG helping us acted as psychologists. They were our psychologists because first thing you need is emotional support" (Parent 1, Discussion Group, October 2012). Affected 1 restated: "Responsibility, even if we don't want it, lies with the SG organisation. Maybe we need to accept it. In the end, the major experts, due to the amount of cases we see and our experiences, are us" (Affected 1, Discussion Group, October 2012). The group, gathering together a great variety of experiences and different backgrounds, has become the ultimate support for parents. In this way, support groups and patient experience were established as new experts and constituting an absolute benchmark in this multidisciplinary action. 
To Professional 5's question, how to implement change?, Professional 2 outlined some potential strategies:

When the doctor hands the control over, very interesting things may happen. For instance, the group wouldn't need many psychologists. The group can find two or three people in the country to contact through Skype. This way, parents will be able to access a psychologist online, right after the diagnosis. There are groups that retain the idea that doctors are at the top of the diagnostic team, but the role of doctors should be that of ensuring that patient takes the lead. Patients could upload their own medical records onto the web and invite experts to provide professional advice and get more than one judgment. This way, you can handle the situation, the information you have. This web-based tool is expensive, but it's a fundamental shift from the model in which doctors had control over the system (Professional 2, Discussion Group, October 2012).

One of the British specialists was certain that in future, care will be centered in that direction:

These are difficult times for doctors. I think our care model is going to move in that direction. But this would have to start out in the support groups. Internet works when it has function within the group. And doctors willing to work in this field would have to adopt this line. Otherwise, they won't work in the field (Professional 2, Discussion Group, October 2012).

Professional 2's consideration suggested some strands of action:

In GrApSIA, we need to look for a psychologist's local network, advice them on this matter so they can support other people. From this network we could coordinate specialists and refer people to them. Parents, people could be offered this service and we could keep in touch to give them some information, to make them feel supported and protected (Affected-Professional 1, Discussion Group, October 2012).

For instance, when I was visiting the SG website, which is what led me to the organisation, I thought it's clearly being underused. If we used a most dynamic tool, as nowadays we're all connected, we surely could discharge many people from some of their duties. There are more dynamic organisations, with blogs, chats... (Affected 2, Discussion Group, October 2012).

Throughout the debate, Professional 2 insisted on the idea that support groups are taking over control with regard to decision-making and management of information. Thus he addressed GrApSIA: 
Doctors are going to find it hard to follow you, because our system is inapplicable to this field. We follow norms, rules based on evidence, which are useless here. There's not possibility for a controlled trial, and we know we can't analyse our outcomes. The only thing we can do is be there for you and learn. And you, as a group, are really strong, I'm impressed. And as a group you're going to be stronger, more prepared to deal with your case, because we are really handicapped (Professional 2, Discussion Group, October 2012).

Unlike other countries, where activist groups have had an important role in questioning the medical paradigm (Cabral, 2009), it appears that in Spain the support groups are the ones directly responsible for a slow change of model (GrApSIA, 2015; Gregori, 2016). They have been a force for change by denouncing secrecy and withholding of information in an "intersexuality/DSD" diagnosis or the way this information is disclosed. The information provided was not only scarce, but also overburdened with gender stereotypes and stigmatization:

When I and my sister were diagnosed 30 years ago, we were diagnosed by the gynaecologist and our family doctor, who was an up-to-date professional, already performing vasectomies, they both said: 'Don't talk about that with your daughters, never'. Not a single word. And then you go: 'There's something wrong with that, they're hiding something...' When I went to see the gynaecologist, I asked him: 'Why do I have breasts?' Doctor answers: 'No, they're not normal breasts, and you have to get used to the idea that you're not going to have the period so, you're not having children. And that's it. And if you want to have sex with men, we'll make you a vagina'. My answer was, 'Then, what do you mean? That we are men?' In his reply: 'No, in fact, girls like you are the epitome of femininity. Girls like you are fashion models' (Affected 3, Discussion Group, October 2012).

All the bodies deviating from the male/female dichotomy are perceived as "abnormal" in our cultural model. Men are conceived as a combination of XY chromosomes, testes, penis, etc.; whereas women are viewed as a combination of XX chromosomes, ovaries, vagina, etc. On the basis of these assumptions, doctors may think disclosure would threaten emotional stability of patients and families, thereby they would withhold it or they would provide it in negative terms. Families store their family secrets away, but guilt and shame are kept present; the "affected" people live in isolation and fear, and the rest of society has never heard of "intersexuality/DSD" or they regard it as something weird, exotic and distant (Gregori, 2015). Breaking that chain of silence and negative information is not a straightforward task, especially when the dichotomous model of sexual normality is so ingrained in our collective unconscious. Affected 2 remembered: 
I've been hindered at home. I wanted to know because I knew there was something wrong. And when I found out it had nothing to do with my ideas. If I told you the odd ideas I had... From the idea that I wasn't their true daughter, that I was a weirdo, to what it really is... The gap is huge (Affected 2, Discussion Group, October 2012).

Affected 3 summed up:

We need to search for the truth. It's about us. My sister found it out before and some years later she shared it with me. One day we came to the doctor and asked for the karyotypes. Not very long time ago. I'm now 47 and when I found out I was 30 , seventeen years ago. The doctor wanted to perform gonadectomy on us. I told him, 'I'm going to search the Internet for information on risks...' The doctor replied: 'Oh! I know, you're gonna be forever young...' And I didn't accept, I've never taken a pill or anything, and now I have osteoporosis and, in some places, ostopenia. One day I came to him, he was already retired and he told me: 'There's no doubt that in these rare cases, we do the best we can' (Affected 2, Discussion Group, October 2012).

Many are the functions that support groups had been undertaking in the care of individuals with an intersex condition, some of which are organized while others are unexpected. The "affected" people taking part in this discussion group put great emphasis on the need to reinforce self-esteem, remove stigmatizing images, as well as redefine the notion of normality. The main action of SG would get fully into what has been known as "normality negotiation" (Cola \& Crocetti, 2011): pri marily for the purposes of individual acceptance, and thereupon in teaching to accept difference and accompanying others, parents, professionals and society at large. Disclosure, education and socialization. Affected 2 underlined:

What child is born perfect? Some are born with a blind eye, or lame, or with just one kidney, or with a defect ear, or whatever else. Then, griev ing should be as in any other case, diabetes, defects or whatever. I don't see a big difference between them. What is necessary is to normalize, but 'normalize' implying it's just as any other situation and all we need to do is face it. To me, the SG is the place you're told: 'Look, this is normal. Your daughter was born with CAIS, PAIS (Partial Androgen Insensitivity Syndrome), green eyes, blond hair... The gap lies in prevalence, some things are more common than the others, but that's all'. We need to find the best solution. It's something that we need to perceive as normal. Just as you accept your kid is diabetic and that they will have to live with in sulin treatments, you accept that your kid has this deformation or forma- 
tion, the way you want to take it (Affected 2, Discussion Group, October 2012).

But negotiating normality is not easy, let alone when it involves sex and sexuality matters. By tabooing this subject we hinder progress within society:

We need to defeat the taboo in sexuality; we can't turn a blind eye. The problem here is to change social outlook [...]. If someone has diabetes, one talks about it. So, in my case, why am I stigmatized? Is it because we're talking about sex? I think the SG duty should be fighting against sexual taboos (Affected 2, Discussion Group, October 2012).

When introducing sexuality, again the support group takes the main role in supporting and caring:

My daughter is still too young, but time will come. We haven't seen a gynaecologist yet, but we'll have to face it, the vagina problem, the sex issue... This matter has already come to my mind. And it makes me feel anxious, just the thought of it, what will it be like (Parent 1, Discussion Group, October 2012).

After this mother expressed her feelings of fear, again the "affected" people taking part in the meeting shared views from their different backgrounds and life experiences:

If it is of any comfort to you, I don't have a vagina, I've never had an operation and I've been married for twenty years. So, don't worry about that. That's her job to do. No need to rush. She'll find her own path. There are options. With AIS, you can live your sexuality fully, in my view. The way you were born. Just like that (Affected 3, Discussion Group, October 2012).

\section{Implementing change: utopia or alternative?}

There are many pressures for the decision-making process to change. In this turn, support groups could have a central or strategic position, as a counterbalance to the lack of institutional resources in intersex/DSD care and attention (and broadly in rare diseases): (1) professionals with limited information, (2) scarce number of multidisciplinary teams (MDT) composed of experts and (3) absence of biopsychosocial care due to the shortage of psychologists in this field (Gregori, 2016). Support groups have been providing support and information from a diversity of experiences: some people have undergone every surgery or treatment available while others have refused them; some are satisfied while others are still suffering; some live in secrecy while others empowered themselves and broke the silence. 
Parents and "affected" people calling upon support groups have the opportunity of taking their own decisions cross-referencing all the information provided by experts, SG and Internet (GrApSIA, 2015).

Broadly, groups formed by people with an intersex condition and their families would correspond with the model of self-support groups; "small groups composed of people with a shared problem" (Katz, 1981, in Canals 2002, p. 62). Conforming to Alfred H. Katz, support groups "gather on a voluntary basis for a specific purpose with a desire for personal or social change. They think their needs are unmet, not addressed by existing institutions. The group offers them the chance for sharing experience, knowledge, hope and strength to deal with their conflict. The group operates without requiring intervention from professionals unless otherwise requested" (in Canals 2002, p. 62). Canals (2002) adds that the following elements appear more or less explicitly: a shared problem; a voluntary nature of the organization; a goal of change (in the lives of their members or in the way to approach the problem); some specific purposes (related to the shared problem); a sharing of knowledge and experience; the requirement to operate without professionals; the small size of the groups and the bolstering and strengthening of self-esteem, identity and responsibility. Behind these features are unmet needs. According to Eduardo Menéndez (1984), other requirement akin to the concept of self-support is the need of horizontal and symmetrical reciprocity forms.

According to this, support groups are presented as crucial to the process of selfacceptance and empowerment. Also, they are central to the difficult task of informing, educating and disclosing intersexuality, as when clinical professionals have limited information, SG offer a broad perspective which allows to weigh the advantages and disadvantages and decide in which direction to go (GrApSIA, 2015; García-Dauder et al., 2015). Affected-Professional 1 related her experience following consultation with two surgeons about redoing vaginoplasty with a different technique after a "failed" intervention:

They were taking decisions about my operation and fixing a date for in tervention and pre-op, pretending I wasn't there... Not to mention it was a skin intervention and I thought: 'no way'. For me, five or ten years ago this would've been... But now, when you're empowered, when you're self-confident and mature enough you almost laugh at what doctors say. If they want to talk to each other in front of me, that's right. And when they come to talk to me, I'll tell them: 'Ok, look, I need to think about it. I'll look into that technique and see if I like it'. But if this happens when you don't know, you have no clue, you're scared; then, doctor's opinion is basic. [Affected 2 added it also depends on age] Age and life moment. Seeing parents with intersexed daughters in the group I understand they 
won't need to face our situations. They would be able to choose and decide freely. So, I look for a doctor who suits me well, who is suitable with what I want. Then, we also need to work on this. Sometimes I think the relationship with doctors is that of the parents: 'What have you done to me, what have you not given me, why don't you listen to me'; Paternalism. And what is our responsibility in this? Have I looked for SG? Have I done some research? Have I asked myself? Have I worked on it? It's really easy to go and say 'you didn't give me this or that, you don't love me...' [Affected 2 stressed that the search is much easier now]. Yes, but now the group is visible. The moment you enter Androgen Insensitivity on the Internet, you find the group [Affected 2 replies that first you need to know it exists]. Because sometimes courage is... Sometimes you don't want to know. You don't want to know, but you want the doctor to sort you out [Affected 2 replies that sometimes you want to know but all you find is obstacles]. Tell me something new! When I was 20 I didn't know what was wrong with me (Affected-Professional 1, Discussion Group, October 2012).

With this model, if there is considerable share of responsibility and work load displaced to SG, the group will be in need of support and outside resources -economic and human - to deal with demand. Currently, GrApSIA's achievements are the result of time and effort made by the members of the group, thus, if responsibility and work were to be greater, SG would need more aids to implement this model. According to Professional 2, there remain more aspects blocking this alternative pathway:

You've developed solutions, and this is raising a problem for many doctors. You are developing solutions for really strong and independent people, like this people here. But there can be other persons not willing to take part or get involved in decision making in a MDT. As doctors, we have to contemplate these people who may seek some guidance. We have to develop strategies and find solutions for those persons not willing to be self-reliant (Professional 2, Discussion Group, October 2012).

In this regard Professional 1 noted:

Over the last few years, patient's movement in Germany is getting stronger, engaging with the process for decision making to have a greater self-reliance. And this is now our objective. But on the other hand there are patients who don't want to play that role. I've done research with cancer patients and in a way it really surprised me when some people asked not to know what would happen. They weren't interested on operations and treatments. They only wanted to know about the possible outcomes and whether they will survive. For example, they didn't know they would have to use a 
pouch [to collect intestinal waste], they didn't ask about it. That's the patient's problem, there are people willing to take part in the process, but there are also passive people. It's really hard for doctors to handle this situation, the type of patients they're dealing with. How to make patients more self-reliant? I don't think there's an answer for this. Maybe we can get to the bottom of the question and see if she wants to know (Professional 1, Discussion Group, October 2012).

But, what other obstacles will we face when implementing this new central role within SG? If patients have an active role in decision-making, they will have to take responsibility for any problems that may arise. Professional 2 clarified:

Doctors need to take a less proactive role in this process leaving the decision-making to the SG's judgment. It is the group that has now this burden. If the group decides the best thing to do is to avoid gonadectomy, for instance, the group is thus responsible if anything goes wrong, if the person develops cancer... Many times, we doctors don't want to pass this burden on the group so we hold it; the responsibility, the burden. I think it's the moment now to pass this responsibility on the group. The responsibility to make a mistake, extended to the patient. When doctors are comfortable with this, they'd be happy (Professional 2, Discussion Group, October 2012).

In prevention of certain health problems, legal and moral responsibility lies somewhat with the medical professionals. Thus, in the shared decision of not removing gonads for some specific intersex/DSD conditions (as in CAIS), if the person develops cancer, who really bears this responsibility? This decision may result in legal issues: "It is therefore difficult to make this adjustment because we are entering the legal landscape. Your doctor may drop the case if you don't follow the instructions you've been given. Who is now responsible for her daughter's risk of cancer? Now this lies with the group as a whole" (Professional 2, Discussion Group, October 2012). In a meeting held by GrApSIA, a doctor had already voiced this tirade that same morning: "You can sue me for this". This type of issues should be considered in proposing new models of shared decision-making between clinicians, patients and parents.

In short, it seems that the most effective alternative would point towards "co-responsibility" in decision-making and care. Professional 4 stated:

We are talking about interpersonal relationships, as simple as that. I admit that besides doctor's duty there is also patient responsibility, when they think the only thing they can do is go asking and asking and asking. No. You, too, are responsible for that. Doctors have their role and patients have theirs. And not go saying, 'You told me that'. Yes, but you had the right not 
to do it. So, why are you blaming me? (Professional 4, Discussion Group, Oc-

tober 2012).

Professional 4's accurate approach omitted to state that such paternalistic attitude in patients is not gratuitous, but the result of a historical doctor-patient relationship. Both parties, as actors in a situation, have learned a role: some command and lead, others listen and obey, and if something goes wrong patients hold doctors accountable. Most doctors expect their indications to be followed, and they do not accept refusal or negotiation. Patients also fear that, if they do not obey, if they request another treatment or another judgment, or if in some specific aspects they prove to know more than the doctor, such challenge could have negative consequence. Affected 3 admitted that, at this time, when patients have access to loads and diverse means of information, things have changed: "I can't talk about other DSD cases, but I know of some AIS cases in which blunders are committed usually. When there was less information, doctor's word was unquestionable and no one contested that. But now that we have more information, doctors are easily questioned" (Affected 3, Discussion Group, October 2012).

To Professional 4 the ideal model should correspond to the concept of selfcare:

What does self-care mean? That patient is given all the information needed to change the paradigm of the doctor-patient relationship. Your attitude shouldn't be that of, 'I oppose everything you say, you are my rival'. After that you can't complain. You need to go and ask some specific questions, about genes and that. It's not the doctor's duty to judge. We are not here to judge you. And that's one of the most important patient's complaints. We are used to complaining and this is a delicate matter. It is all about education, but also sensitivity... As Professional 2 stated, doctors aren't going to budge one inch, from their lofty place. We all have our lofty place. Someone has to topple you from there, because you won't move. Developing the concept of self-care, like in any chronic disease: diabetes, cancer, thyroidism... That's the idea (Professional 4, Discussion Group, October 2012).

But for a real and effective shared decision-making, as some new research studies expose, we raised that it would be necessary for medical professionals to acknowledge the absence of evidence in the need for early procedures, the lack of studies that propose prospective long-term evaluations of the psychological impact of sex assignment surgeries and also the quality of such studies, which is related to the use of inconsistent methodology to evaluate intervention outcomes (Machado et al., 2015). In this sense, Machado et al. (2015) points out that clinical practitioners should guarantee in- 
tersex people and their relatives access to a wide range of information, counseling and comprehensive care.

Finally, and in order to close the debate, we posed the following question: if the main problem refers to the way our culture understands bodies and sexes, that is to say, sociocultural aspects, in which direction could all the affected actors work? How can we introduce social intervention beyond medical intervention in the Spanish context? Professional 6 enumerated some possible strategies: (1) To encourage training workshops on sexual and bodily diversity, addressed to medical professionals - doctors, psychologists, etc.- and society at large; (2) To elaborate and disseminate brochures and other educational material on intersexuality; (3) To broaden the teaching curricula at medical schools, including gender and sexuality studies changing the social perspective on DSD/intersex conditions; (4) To review teaching units in primary and higher education levels, including human variability, sexual and functional diversity in a non-pathologized approach:

If from childhood, and later when they go to university, whenever... If we knew that there are XX women, and in a lower frequency, XY women, maybe when a woman finds out her chromosomes are XY she wouldn't be traumatized, we could talk about it naturally (Professional 6, Discussion Group, October 2012).

Affected 2 added:

I studied that in COU [last year before university]. I understood what they said about it but at no point I connected it with myself. It had been always alien and foreign to me. When they explained it, what I saw was a monster, figuratively, something like that. When I found out about me, one of that cases that I thought of as a monster, I said, 'Either I am very absent-minded or I haven't understood anything'. I think that what we need to do is to teach this stuff making it appear normal (Affected 2, Discussion Group, October 2012).

Professional 3 and Affected 1 appeared more skeptical on the relevance of explaining diversity at school:

In my opinion, what is out of logic is to explain that besides $\mathrm{X}$ and $\mathrm{Y}$, that is girl and boy, there is infinite variation. To me, these two possibilities, if everything is alright these are the possibilities. It's true that there are others, but that only happens when something goes wrong. [...] In every organism there is variation. There are people with sublingual thyroid or with no thyroid, so they suffer hypothyroidism. Biological explanations to children don't 
include pathologies. You can tell them there are thyroid variants or liver or pancreas variants (Professional 3, Discussion Group, October 2012).

I don't think it's realistic to change society's view for something not so common. The change we need is respect of the unknown. We don't need to talk about the existence of XY women. Anyway, [that variation] is infinite. And it would be two years instead of one week at school. [...] Maybe that's a terminology thing, but this is about life. People are not good or bad, like in Batman. This is important. It's a very important thing to learn. There relies respect and good attitude towards difference (Affected 1, Discussion Group, October 2012).

Professional 5 disagreed: "transexuality is far less common than intersexuality but no one knows about intersex. [...] It isn't that hard to explain things in a non narrowminded view but with a range of possibilities" (Professional 5, Discussion Group, October 2012).

\section{Conclusions}

Patricia Martin (2003) reflected on the impact Internet had had when modifying Intersex standards of care, to conclude that in the lack of long-term studies and in the face of traumatic revelations within the intersexed community, "a time to slow down, a time to think and a time to listen to the voices of the intersexed" (p. 169) is necessary. This time out, this need for listening and discussing might be extrapolated to the Spanish context. It is time to stop and listen to all the voices. Patient views and experience must be privileged as they are the ones living within the diagnosis, and search for the best choices together. Only in this way can care be enhanced and can old stigmas be broken.

Unquestionably, there remains work to be done. But we are convinced that meetings and discussions like the Bioethics and Intersex/DSD Work Group will make it possible to advance towards a new model on intersex health care and management. Admittedly, we have noticed a change of model from what has been expressed in these discussions: new actors have appeared and there have been some shifts in responsibility and care. More particularly, there are some key points to underline as they constitute strategic places to work: (1) We need to contemplate structural and organizational particularities of every national health system -in this case, the Spanish -, when designing intersex/DSD standards of care. (2) We have ascertained the desire for change in the doctor-patient relationship, leading towards a "self-care model" -patient-centered care, where patient will become part in the MDT, but also where every 
social actor must assume responsibility. (3) The medical sphere as main subject matter has been displaced. Thus, solutions are now searched in "psychosocial care" and through the "transformation of sociocultural conceptions". More specifically, we believe this could be possible by psychologically supporting the intersex in fighting fear of difference. Also, leading parents and other family members in the uncertainty and acceptance process, and finally, transforming rigid cultural models that reject identity and anatomic variability (Alcántara, 2012; Gregori, 2015).

In this new model, support groups could gain autonomy and eventually become the main actors in intersex care. As with other countries, support groups in Spain could take the relay from the medical professionals in respect of information management and decision-making. Thus, the trend is that active patients emerge as expert agents and lobbies of pressure groups when it comes to structural -socio-health care structure, organization and medical practice-, familiar and social transformations. They could consolidate their role in the "normality negotiation process" assuming their pedagogic function in a triple task: identity foreclosure, education and socialization. Support groups are breaking the chain of silence and negative connotations. Also, they are revealing that sexuality models are plenty of gender stereotypes. In this regard, tools provided by Information and Communication Technologies, such as Internet directories and search engines, have been crucial and will remain so.

\section{Referencias}

Alcántara, Eva (2012). Llamado intersexual. Discursos, prácticas y sujetos en México (Doctoral dissertation). Universidad Autónoma Metropolitana, México.

Baechler, Marie-Noëlle (2006, 29 August). Children are not disorders [Editor letter]. Archives of Disease in Childhood. Retrieved from: http://adc.bmj.com/content/91/7/554.responses\#children-are-not-disorders

Bartlett, Yvone Kiera \& Coulson, Neil S. (2011). An investigation into the empowerment effects of using online support groups and how this affects health professional/patients communication. Patient Education and Counselling, 83(1), 113-119. https://doi.org/10.1016/j.pec.2010.05.029

Cabral, Mauro (Ed.) (2009). Interdicciones. Escrituras de la intersexualidad en castellano. Córdoba: Anarrés.

Canals, Josep (2002). El regreso de la reciprocidad. Grupos de ayuda mutua y asociaciones de personas afectadas en la crisis del Estado de Bienestar. Unpublished Doctoral dissertation, Universitat Rovira i Virgili, Tarragona.

Cola, Mirna \& Crocetti, Daniella (2011). Negotiating normality: experiences from three Italian patients support group. Kroeber Anthropological Society, 99/100(1), 214-236. 
Creighton, Sarah M.; Minto, Catherine L.; Liao, Lih-Mei; Alderson, Julie \& Simmonds, Margaret (2004). Meeting between experts: evaluation of the first UK forum for lay and professional experts in intersex. Patient Education \& Counselling, 54(2), 153-157. https://doi.org/10.1016/S0738$\underline{3991(03) 00202-7}$

Cull, Melissa L. (2002). Treatment of intersex needs open discussion. BMF, 324(7342), 919. https://doi.org/10.1136/bmj.324.7342.919

Cull, Melissa L. (2005). A support group's perspective. BMF, 330(7487), 341. https://www.bmj.com/content/330/7487/341

Cull Melissa L. \& Simmonds M. (2010). Importance of Support Groups for Intersex (Disorders of Sex Development) Patients, Families and the Medical Profession. Sexual Development, 4(4-5), 310-312. https://doi.org/10.1159/000313889

Damiani, Durval (2006, 19 July). Ambiguous terms still persist in the Consensus [Editor letter]. Archives of Disease in Childhood. Retrieved from: http://adc.bmj.com/content/91/7/554.responses\#ambiguous-terms-stillpersist-in-the-consensus

Diamond, Milton \& Beh, Hazel (2006, 27 July). Variations of sex development instead of disorders of sex development [Editor letter]. Archives of Disease in Childhood Online. Retrieved from:

http://adc.bmj.com/content/91/7/554.responses\#ambiguous-terms-stillpersist-in-the-consensus

Diamond, Milton \& Sigmundson, Keith (1997). Sex Reassignment at Birth: A Long Term Review and Clinical Implications. Archives of Pediatrics and Adolescent Medicine, 151(3), 298-304. https://doi.org/10.1001/archpedi.1997.02170400084015

Dreger, Alice (1999). Intersex in the Age of Ethics. Maryland: University Publishing Group.

Ford, Kristen (2001). "First, do no harm" - the fiction of legal parental consent to genital-normalizing surgery on intersexed infants-. Yale Law Policy Rev., 19(2), 469-488.

García-Dauder, (S.) \& Romero, Carmen (2012). Los desplazamientos políticos de las categorías médicas: Actores, discursos, y relaciones en la controversia 'Disorders of sex development' versus 'Intersex'”. In Eulalia Pérez Sedeño \& Rebeca Ibáñez (Eds.), Cuerpos y diferencias (pp. 213-240). Madrid: Plaza y Valdés.

García-Dauder, (S.), Gregori, Nuria \& Hurtado, Inmaculada (2015). Usos de lo psicosocial en la investigación y tratamiento de las intersexualidades/DSD. Universitas Psychologica, 14(5), 1649-1666. http://dx.doi.org/10.11144/Javeriana.upsy14-5.piti

Geertz, Clifford (1973). The Interpretation of Cultures. New York: Basic Books.

Goodall, Harold (2000). Writing the new ethnography. Lanham: AltaMira Press/Rowman \& Littlefield. 
GrApSIA (2015). Tratamiento y afrontamiento del SIA: Una tarea compartida. Revista Española de Endocrinología Pediátrica, 6(2), 28-34. https://doi.org/10.3266/RevEspEndocrinolPediatr.pre2015.Nov.329

Greenberg, Julie (2012). Health Care Issues Affecting People with an Intersex Condition or DSD: Sex or Disability Discrimination? Loyola of L.A. Law Review, 45(3), 849-908.

Gregori Flor, Nuria (2015). Encuentros y des-encuentros en torno a las intersexualidades/DSD. Narrativas, procesos y emergencias (Doctoral dissertation). Universidad de Valencia, Valencia.

Gregori Flor, Nuria (2016). Diagnòstic de les diferents realitats, posicionaments $i$ demandes de la població intersexual/amb DSD (diferències del desenvolupament sexual) a Barcelona. Barcelona: Àrea de Drets de Ciutadania, Participació i Transparència. Direcció de Feminismes i LGTBI. Ajuntament de Barcelona.

Hinkle, Curtis E. (2010). ¿A quién pertenece nuestro cuerpo? In Jorge I. Raices (Comp.), Un cuerpos, mil sexos. Intersexualidades (pp. 37-41). Buenos Aires: Topia.

Kessler, Suzanne (1998). Lessons from the Intersexed. London: Rutgers Univ.Press.

Kipnis, Kenneth \& Diamond, Milton (1999). Pediatric Ethics and the Surgical Assignement of Sex. In Alice Domurat Dreger (Ed.), Intersex in the age of ethics (pp. 119-137). Maryland: University Publishing Group.

Lee, Peter A.; Houk, Christopher P. ; Ahmed, S. Faisal \& Hughes, Ieuan A. (2006). Consensus statement on management of intersex disorders. Pediatrics, 118(2), 488-500. https://doi.org/10.1542/peds.2006-0738

Machado, Paula Sandrine (2008). Intersexualidade e o "Consenso de Chicago". As vicissitudes da nomenclatura e suas implicações regulatórias. Revista Brasileira de Ciências Sociais, 23(68), 109-124. http://dx.doi.org/10.1590/S0102-69092008000300008

Machado, Paula Sandrine; Costa, Angelo Brandelli; Nardi, Henrique Caetano;

Vaitses Fontanari, Anna Martha; Araujo, Igor Rabuske \& Knauth, Daniela Riva (2015). Follow-up of psychological outcomes of interventions in patients diagnosed with disorders of sexual development: A systematic review. Journal of Health Psychology, 21(10), 2195-2206. https://doi.org/10.1177/1359105315572454

Martin, Patricia (2003). Moving toward an international standard in informed consent: the impact of intersexuality and the Internet on the standard of care. Duke Journal of Gender Law \& Policy, 9, 135-169.

Menéndez, Eduardo (1984). El modelo médico hegemónico: transacciones y alternativas hacia una fundamentación teórica del modelo de autoatención en salud. Arxiu d'Etnografia de Catalunya, 3, 85-119.

Morris, Esther (2001). The missing vagina monologue. Sojourner Women's Health Edition. Retrieved from: http://mrkh.org/articles/the-missing-vaginamonologue-and-beyond/ 
Preves, Sharon (2003). Intersex and Identity. New Brunswick, New Jersey and London: Rutgers University Press.

Reis, Elisabeth (2007). Divergence or Disorder: the politics of naming intersex. Perspectives in Biology and Medicine, 50(4), 535-543. https://doi.org/10.1353/pbm.2007.0054

Sieldberg, Sophia (2006, 18 August). The terms need to evolve [Editor letter]. Archives of Disease in Childhood. Retrieved from: http://adc.bmj.com/content/91/7/554.responses\#ambiguous-terms-stillpersist-in-the-consensus

Simmonds, Margaret (2006, 17 August). Was Variations of Reproductive Development considered? [Editor letter]. Archives of Disease in Childhood. Retrieved from: http://adc.bmj.com/content/91/7/554.responses\#ambiguous-terms-stillpersist-in-the-consensus

Tamar-Mattis, Anne (2008, November). Medical decision-making and the child with a DSD. Endocrine Today. Retrieved from:

https://www.healio.com/endocrinology/pediatricendocrinology/news/print/endocrine-today/\%7B17caf5fa-433f-4bc6-8d124b2a299f3e1a\%7D/medical-decision-making-and-the-child-with-a-dsd

Wainwright, David (1997). Can Sociological Research be Qualitative, Critical and Valid? The Qualitative Report, 3(2). Retrieved from: http://www.nova.edu/ssss/QR/QR3-2/wain.html

Warne, Garry (2003). Support Groups for CAIS and AIS. Conference Proceedings: Genetic and Hormonal Basis of Sexual Differentiation Disorders, 13(3),175178.

Wiesemann, Claudia; Ude-Koeller, Susanne; Sinnecker, Gernot \& Thyen, Ute (2009). Ethical Principles and Recommendations for the Medical Management of Differences of Sex Development (DSD)/Intersex in Children and Adolescents. European fournal of Pediatrics, 169(6), 674-676. https://doi.org/10.1007/s00431-009-1086-x

Wilson, Bruce \& Reiner, William (1998). Management of Intersex: A Shifting Paradigm. The fournal of Clinical Ethics, 9(4), 360-370.

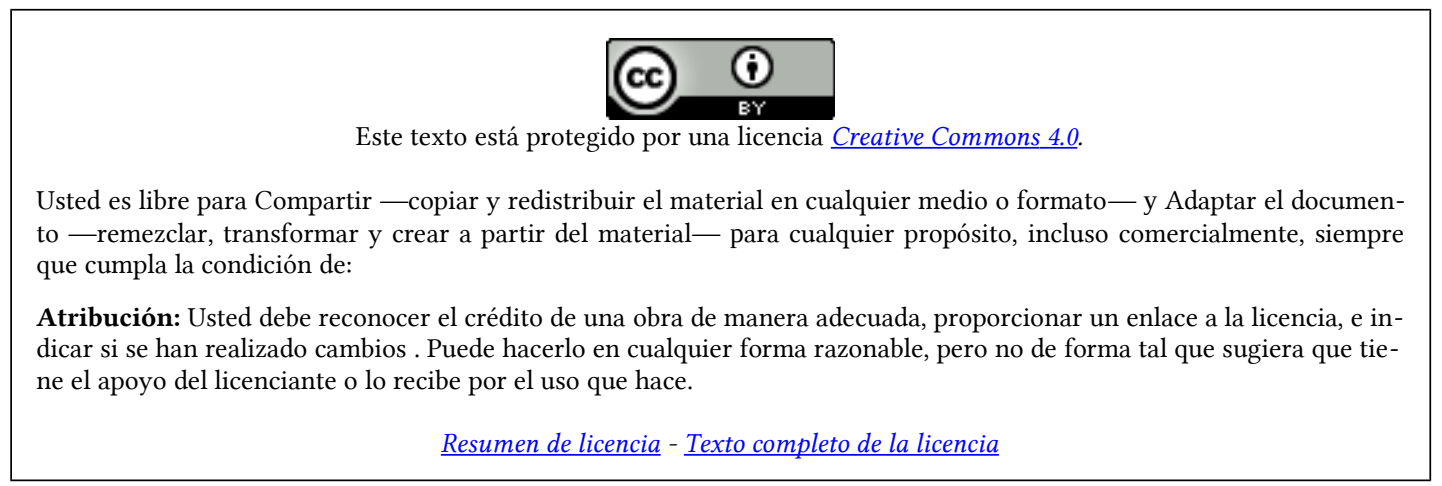

